Article

\title{
Enhanced Tight Oil Recovery by Volume Fracturing in Chang 7 Reservoir: Experimental Study and Field Practice
}

\author{
Long Yu ${ }^{1,2}$, Jinjie Wang ${ }^{1, * \mathbb{D}}$, Chong Wang ${ }^{3}$ and Daixin Chen ${ }^{4}$ \\ 1 Key Laboratory of Tectonics and Petroleum Resources (China University of Geosciences), \\ Ministry of Education, Wuhan 430074, China; long.yu@ucalgary.ca \\ 2 Department of Chemical Engineering, University of Calgary, Calgary, AB T2N1N4, Canada \\ 3 Research Institute of Exploration \& Development, Changqing Oilfield Company, PetroChina, Xi'an 710018, \\ China; wch_cq@petrochina.com.cn \\ 4 No. 12 Oil Production Plant, Changqing Oilfield Company, PetroChina, Xi'an 710018, China; \\ chenzx_cq@petrochina.com.cn \\ * Correspondence: wangjinjie@cug.edu.cn
}

Received: 13 May 2019; Accepted: 19 June 2019; Published: 24 June 2019

check for updates

\begin{abstract}
The Chang 7 reservoir in Changqing oilfield is rich in tight oil. However, due to the low formation permeability, it is very difficult to obtain economical oil production without stimulation treatments. Volume fracturing seems to be a more efficient tight oil recovery enhancement (EOR) method in Chang 7 pilot tests compared with conventional hydraulic fracturing. In this study, Chang 7 tight oil reservoir was first characterized by its geological property, hydrocarbon source rock distribution, and formation physiochemical property. Tight core flooding tests were then conducted to experimentally investigate the EOR ability of the volume fracturing technique. The field-scale practice was also demonstrated and analyzed. The results show that Chang 7 reservoir is favorable for the generation of a large amount of tight oil. Fractures created in tight cores can significantly improve the fluid flow conductivity and enhance the imbibition of displacing water, resulting in a greater tight oil recovery increment. Volume fracturing is an effective way to generate a larger number of fractures. Field application indicates that volume fracturing treatment can form a much greater reservoir stimulation volume. Daily oil production in the volume-fracturing-treated wells can be more than twice as high as that in the conventional-fracturing-treated wells.
\end{abstract}

Keywords: volume fracturing; Chang 7 reservoir; tight oil recovery; imbibition; oil production

\section{Introduction}

With the world's increasing need for energy and the gradual decline of conventional oil and gas production, attention has been turned toward unconventional reservoirs such as shale oil and shale gas [1]. Resources in tight reservoirs are substantial worldwide. Global gas reserves in shale reservoirs are estimated to be 716 trillion $\mathrm{m}^{3}$ [2]. America has turned unconventional resource production into a commercial process. Tight sand production and shale gas account for about $30 \%$ of total gas production in America [3]. China has the largest natural gas resources in tight reservoirs or tight sand reservoirs [4,5]. However, although there is large resource potential in tight reservoirs, it is much more difficult to extract oil and gas from a tight formation than from conventional reservoirs, mainly due to the small pore size and the ultra-low permeability of the matrix [6,7].

Hydraulic fracturing combined with horizontal drilling has been widely used to enhance the production of oil and gas from tight sands or shale reservoirs [8,9]. Hydraulic fracturing improves hydrocarbon transport by increasing the formation's permeability and enhancing extraction. The main 
approach is to cut the low-permeability matrix into small pieces to increase the rock surfaces and connectivity. The fine induced fractures maximize the area of contact with the rocks, allowing hydrocarbon extraction from thousands of meters of rocks, rather than tens or hundreds of meters available with merely vertical wells $[10,11]$. Fracture networks connect each small piece of the matrix to the hydrocarbon flow path to the production well [12,13]. Many successful cases worldwide demonstrate that hydraulic fracturing enhances oil recovery in unconventional reservoirs [14,15]. Hydraulic fractures connecting with natural fracture systems ensure a more effective stimulation in fractured reservoirs, but the occurrence of arrest, diversion, and offset may inhibit the fracture growth and proppant placement. Blanton's [16] conducted laboratory hydraulic fracturing experiments using pre-fractured material to investigate the interactions between hydraulic fractures and natural fractures, aiming to provide information that helps to examine the conditions under which such inhabitations happen so that detrimental effects can be prevented. His results show that the morphology of hydraulic fracture is significantly affected by the pre-existing fractures, and hydraulic fractures are more likely to cross natural fractures only in high stresses and under high pre-existing fracture angles. Maity and Ciezobka [17] developed a novel image-processing workflow method to detect and analyze the proppant distribution in more than 200 through-fracture Permian Basin core samples to investigate proppant transport behavior in stimulated formation volumes during hydraulic fracturing treatment. The observations show that the presence of hydraulic fracture and of natural fracture and their interactions do not necessarily result in high proppant concentration in the cores, and stress contrast and lithology changes can govern the local in-depth proppant distribution. Their study provides a new method to systematically analyze core samples for the distributions of proppant and similar particles. Cipolla et al. [18] identified the benefits of tortuosity, multiple fractures, and the apparent activation of natural fractures and verified their potential using both fracture modeling and G-function analyses. Luo et al. [19] conducted a reservoir simulation using a geo-model to simulate the unique flow regime in multi-stage fractured horizontal wells compound formation linear flow. Results showed good agreement with field data of the Bakken formation.

In recent years, due to the rapid development of the tight oil/gas industry, the oil/gas recovery technique has made great progress. The appearance of volume fracturing has resulted in a great increase in tight oil and gas production [20]. The conventional hydraulic fracturing treatment aims to create a bi-wing open fracture in tight reservoir formations [21]. The fluid flowability is mainly affected by one fracture, but the fracture cannot improve the flowability of the total reservoir formation because, in the vertical direction of the fracture, the oil/gas still experiences a long-distance matrix flow in the low permeability porous media, as shown in Figure 1a. The single fracture limits the final oil/gas recovery efficiency, as the fluid flowability in the vertical direction is not increased [22,23]. To improve reservoir productivity, the fracture should be designed with a high fracture length and a high fracture conductivity [24]. The volume fracturing technique can generate single open fractures and can create and extend complex fracture networks $[23,25]$. In volume fracturing treatment, the reservoir formation was reconstructed and broken up through the fracturing method, forming several main fractures. By using the high flux, a large volume, and low viscosity fluids, together with the "staged and multi-cluster" perforation, secondary fractures can be generated in the main fractures. In the same way, second-order secondary fractures, and third-order secondary fractures, can also be created to form a complex fracture network in the formation $[25,26]$, as shown in Figure 1b. The volume of the formation with fracture networks is called the stimulated reservoir volume (SRV) [27,28].

Fractures generated by volume fracturing are not only conventional open fractures, they also experience a shear/sliding dilation process [29], which leads to larger contact areas between the fracture faces and formation matrix. Due to the great number of created fractures, the complex fracture network and the large fracture-contact area, the oil/gas in the stimulated reservoir formations can flow along the shortest distance in any direction from the matrix to the fractures, significantly increasing the overall formation permeability $[25,26,30]$. Therefore, the reservoir formation can be effectively reconstructed, and reservoir productivity can be greatly improved. 


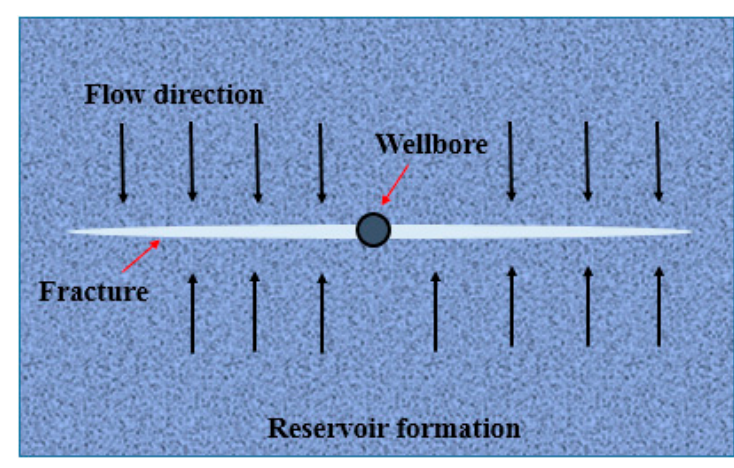

(a)

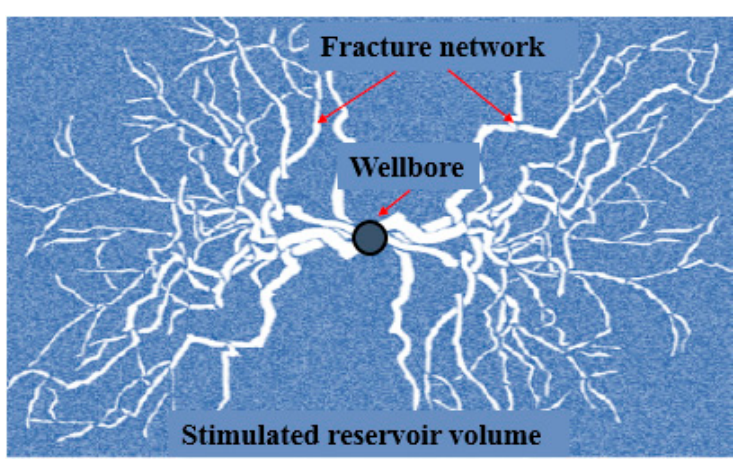

(b)

Figure 1. Schematic of conventional hydraulic fracture and fracture network by volume fracturing: (a) Conventional fracture, (b) fractures by volume fracturing treatment.

Both conventional fracturing and volume fracturing are sand fracturing techniques. According to some criteria, sand fracturing treatment with a fracturing fluid volume smaller than $1500 \mathrm{~m}^{3}$ is called conventional fracturing, and that with a fracturing fluid volume larger than $1500 \mathrm{~m}^{3}$ is called volume fracturing [31]. However, volume fracturing still has other characteristics in terms of operations. In volume fracturing, the fluid injection rate is relatively high, usually larger than $10 \mathrm{~m}^{3} / \mathrm{min}$, but it can be slightly smaller in some specific reservoirs. Volume fracturing is usually operated with a smaller proppant (70/100 mesh $40 / 70$ mesh) and a lower sand ratio, with an average range of 3-5\%. In some cases, the sand ratio can be around $10 \%$, depending on the formation properties. Slickwater is mostly used as the fracturing fluid [32,33]. In some conventional fracturing theories, the injection of a significant volume of fracturing fluids with high pressures would cause a serious filter loss problem of the fluid in the matrix and forming shorter hydraulic fractures, resulting in formation damage and non-effective fracturing treatment. However, volume fracturing treatment always accompanies by injection of large volume fracturing fluids. First, this is because the segmented multi-cluster fracturing technique is usually employed in the volume fracturing treatment to form fracture networks [34-36]. In conventional staged fracturing treatment in horizontal wells, the single cluster perforation method is usually used, which can only support the low volume and low rate of fracturing fluid injection, not the large fluid injection required by the multi-cluster fracturing. Second, the volume fracturing is more suitable for and usually being applied in brittle formations, which are more easily to form a great number of complex fractures during the large volume injection fracturing treatments. Third, because of the low permeability of tight oil rocks, the filtration loss of fracturing fluids to the matrix is very small, most of the large volume fluids would flow into the numerous induced fractures or the natural microfractures, which could increase the stimulated reservoir volume. Study results from Li et al. [37] show that volume fracturing can significantly increase the production of tight oil reservoirs. A larger fractured volume and increased fracture networks could result in greater oil production. Chen et al. [31] compared the investment and benefit between conventional hydraulic fracturing and volume fracturing in the Southern Sichuan Basin and found that tested gas production yield from volume fracturing is about 2.12 times that of conventional fracturing technology. The wide application of volume fracturing in the field could reduce the circle returns and decrease total costs.

The Changqing oilfield is a regional oilfield affiliated with PetroChina Company Limited (PetroChina). In 2012, the oil-gas equivalent exceeded 45 million tons, making it the biggest field in China. The work area is located in the Ordos Basin, with an exploration area of $3.7 \times 105 \mathrm{~km}^{2}$. Chang 7 is a block rich in tight oil with estimated resources reaching up to two billion tons. Hydraulic fracturing has been tried for tight oil recovery in Chang 7. However, pilot tests and field data show that conventional hydraulic fracturing treatments cannot efficiently improve the oil production rate, whereas volume fracturing treatment in the Chang 7 tight oil formations can lead to a significant increase in the tight oil production and a great decrease in the water cut. 
In this study, the geological and physical properties of Chang 7 tight oil reservoir were characterized first. The tight oil recovery ability of the volume fracturing treatment was investigated through core flow experiments and field scale practice. The results of this work may provide some instructions with the applicability of the volume fracturing technique in tight oil reservoirs for EOR.

\section{Characterization of Chang 7 Tight Oil Reservoir}

\subsection{Geological Characteristics}

Figure 2 shows the location and typical sedimentary facies of the Chang 7 reservoir, the Changqing oilfield. Chang 7 is the main tight oil reservoir in China and is located in the Ordos Basin. The Ordos Basin is a typical inland sedimentary basin with a multiphase craton in the southwest of North China. Delta facies and lacustrine facies were widely developed in the Ordos Basin. The delta front sand bodies, the gravity current settled sediments in semi-deep-deep lake faces, and the turbidity sand bodies are the most important reservoir sand bodies for Chang 7 . The reservoir sand bodies are close to the hydrocarbon source rocks, possessing favorable conditions for the accumulation of tight oil.

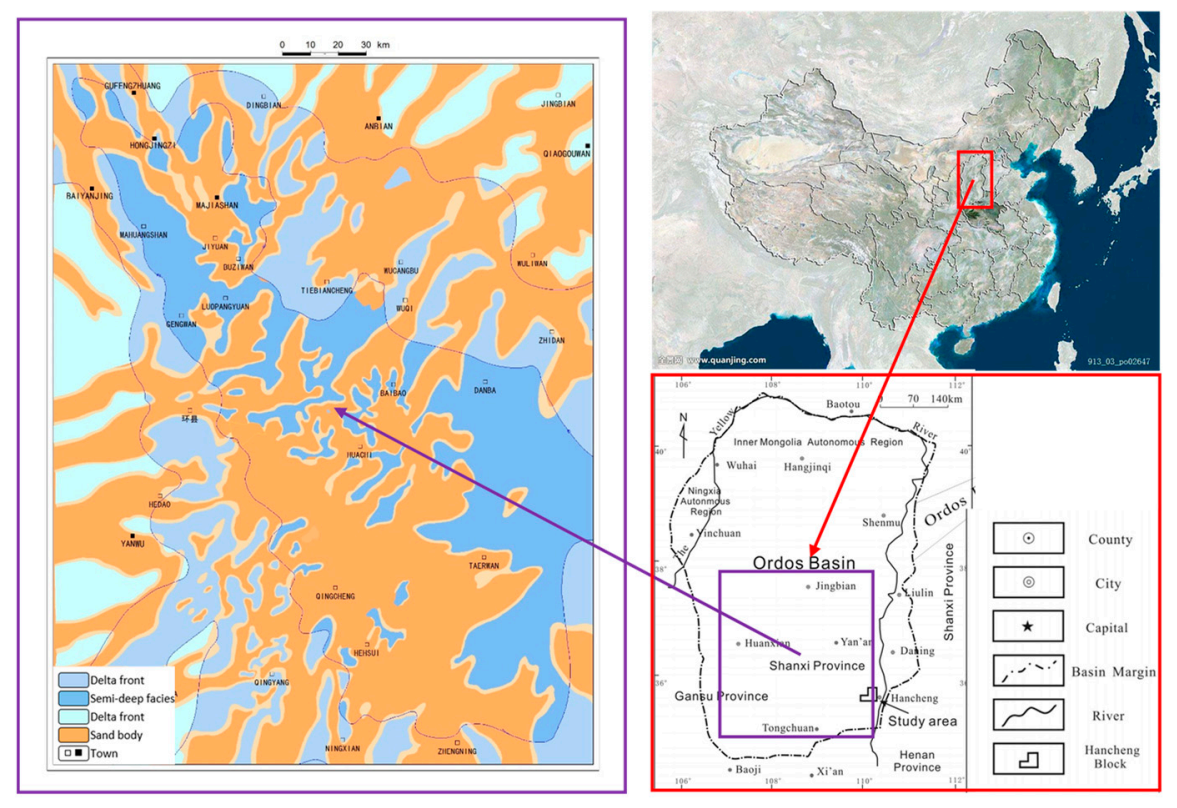

Figure 2. Location of the Ordos Basin together with typical sedimentary facies and sand body distributions of the Chang 7 tight oil reservoir, the Changqing oilfield.

\subsection{Characteristics of Hydrocarbon Source Rocks}

The hydrocarbon source rocks of Chang 7 are mainly composed of oil shale and dark mudstone. Figure 3 shows the isoline graphs of the thickness of the source rock distributions in Chang 7, the Ordos Basin. The oil shale, found largely at the bottom of the Chang 7 oil reservoir group, distributes in the NW-SE direction, reaching ZhiDan at the northeast, Majiatan at the northwest, Zhenyuan-Jingchuan at the southwest, and Yijun-Huangling at the southeast, and it is estimated that $37 \%$ of the total volume of source rocks in this area are oil shale, with an average thickness of $16 \mathrm{~m}$ and a total area of $3.25 \times 104 \mathrm{~km}^{2}$, as shown in Figure 3a. The hydrocarbon generation center for oil shale is at Jiyuan-Huachi-Zhengning. Compared with oil shale, the dark mudstone possesses a wider distribution. It reaches Ansai at the northeast, Majiatan at the northwest, Pingliang at the southwest, and Huanglong at the southeast, and the distribution of mudstone covers an area of $5.11 \times 104 \mathrm{~km}^{2}$ in the direction of NW-SE, with an average thickness of $17 \mathrm{~m}$, as shown in Figure $3 \mathrm{~b}$. The mudstone occupies $63 \%$ of the total volume of source rocks. 
0 $\quad 20 \quad 40 \quad 60 \mathrm{~km}$

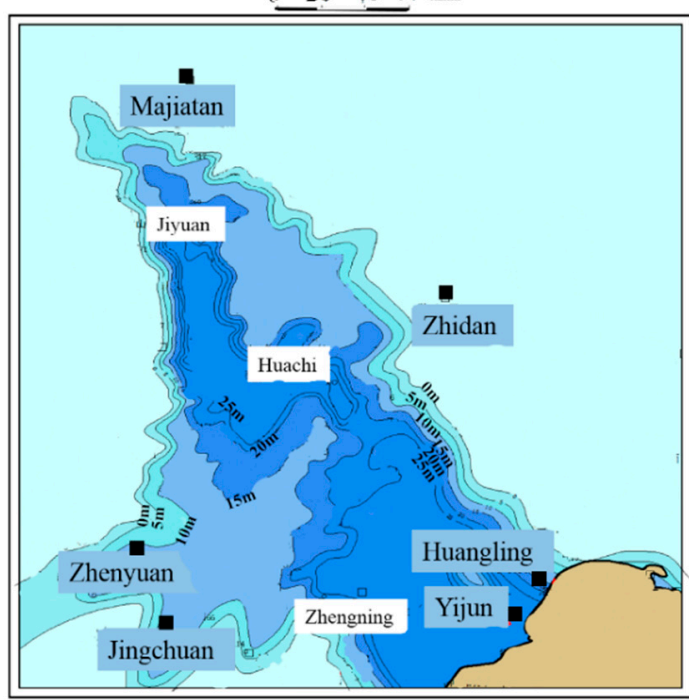

(a)
$0 \quad 20 \quad 40 \quad 60 \mathrm{~km}$

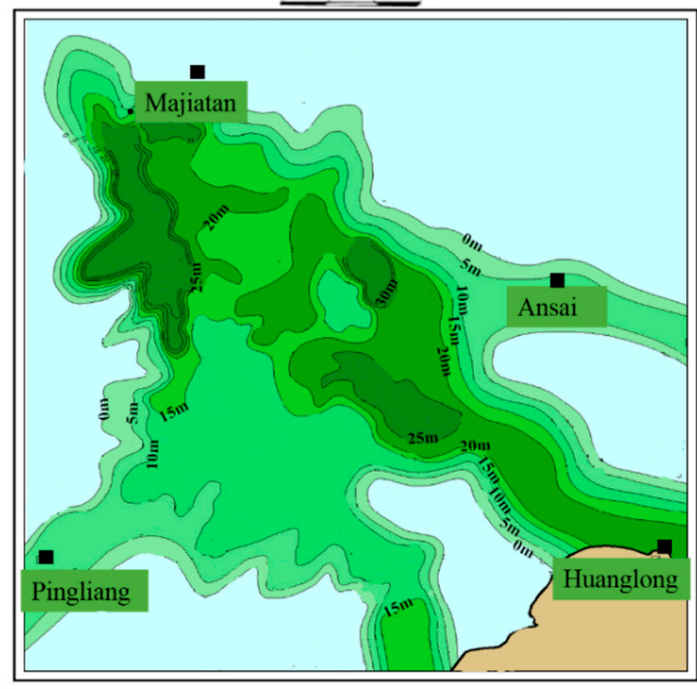

(b)

Figure 3. Isoline graph of the thickness of hydrocarbon source rock distributions in Chang 7, the Ordos Basin: (a) Oil shale, (b) dark mudstone.

The total organic carbon (TOC) is an important characterization parameter of the organic matter abundance in hydrocarbon source rocks. In this study, 123 core samples from Chang 7 were first collected, and a carbon and sulfur analyzer (CS analyzer, model: CS 230, LECO, St. Joseph, MO, USA) was used to measure the TOC in the hydrocarbon source rocks. The CS 230 analyzer can conveniently measure the TOC data with high accuracy and high stability, with a $1 \mathrm{ppm}$ or $5 \%$ relative standard deviation (RSD) measurement accuracy. Hydrocarbon source rocks of Chang 7 are rich in organic matter. Organic geochemical data indicate that the residual organic carbon content in the hydrocarbon sources rocks mainly distributes in the range of $2-22 \%$. In some source rocks, the residual organic carbon content can be as high as $30-40 \%$. Figure 4 shows the distributions of the total organic carbon (TOC) for dark mudstone and oil shale in the Chang 7 reservoir. It can be seen that TOC for dark mudstone is smaller than 10, it mainly concentrates in the range of two to five. While for oil shale, the TOC has a wider range from 2 to 25 . The average TOC for dark mudstone and oil shale is $5.8 \%$ and $13.8 \%$, respectively.

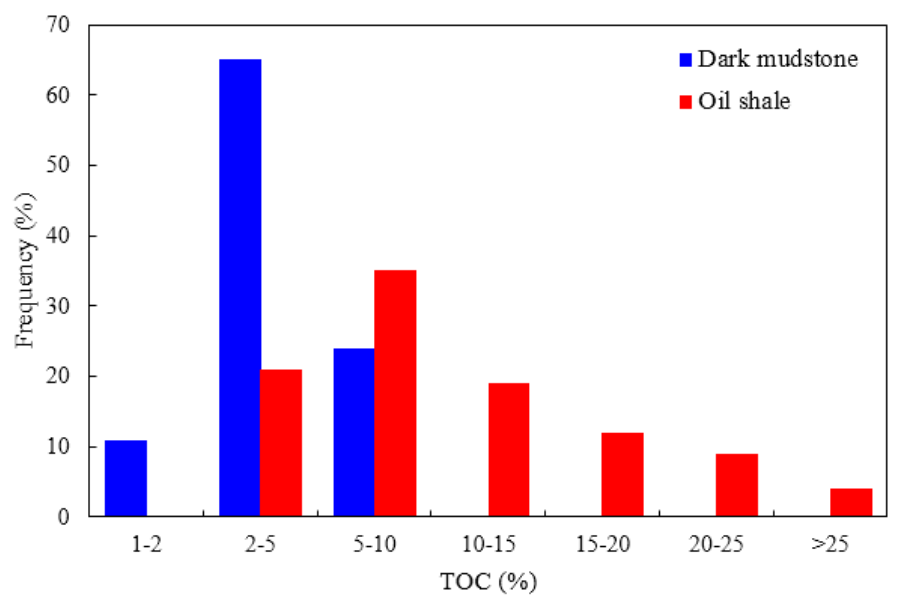

Figure 4. TOC distribution for source rocks in Chang 7 in the Ordos Basin.

The corresponding vitrinite reflectance (Ro) for the source rocks of the Chang 7 reservoir is between $0.85 \%$ and $1.15 \%$, indicating a high intensity of hydrocarbon generation. It is estimated that 
the average intensity of hydrocarbon generation in Chang 7 is $495 \times 10^{4} \mathrm{~km}^{2}$. The total amount of generated hydrocarbons in the source rocks can be as high as $2473.08 \times 10^{8}$ ton. The source rocks also experienced a strong hydrocarbon expulsion process, with a hydrocarbon expulsion intensity of $290 \times 10^{4} \mathrm{~km}^{2}$, and a hydrocarbon expulsion amount of $1447.71 \times 10^{8}$ ton. It can be seen that the Chang 7 reservoir in the Changqing oilfield possesses a significant amount of favorable hydrocarbon source rocks, which ensures a high capacity for generating and producing oil.

\subsection{Physical Properties of Reservoir Formations}

Testing data collected from four pilot areas, Maling, Heshui, Jiyuan, and Ansai, in Chang 7 were used to characterize the physical properties of the tight oil reservoir formations. Figure 5 shows the location distribution of the four pilot areas. As can be seen, the pilot areas covered most of the typical formations in the Chang 7 tight oil reservoir, so the physical properties results measured in these areas can be used to characterize the overall physical properties for Chang 7 .

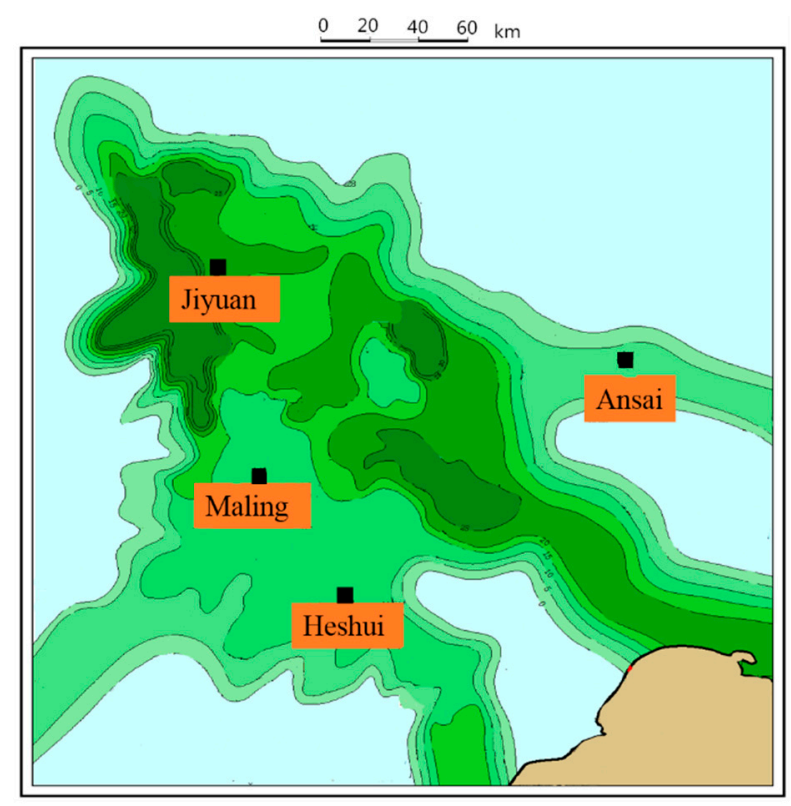

Figure 5. Locations of the four pilot areas in Chang 7 reservoir.

Table 1 gives the detrital components of the tight reservoir rocks of the four pilot areas in Chang 7. It can be seen that the tight sandstones are mainly composed of quartz, feldspar, and lithic fragments, which occupy $77.3 \%$ of the total composition analyzed through a number of rock samples. Therefore, the formation rocks possess a high brittleness and tend to form complex fractures during fracturing treatments.

Table 1. Detrital components for the four pilot areas in Chang 7.

\begin{tabular}{cccccc}
\hline \multirow{2}{*}{ Pilot Area } & \multirow{2}{*}{ Number of Sample } & \multicolumn{4}{c}{ Detrital Composition [\%] } \\
\cline { 3 - 5 } & & Quartz & Feldspar & Lithic Fragment & Others \\
\hline Maling & 68 & 40 & 18.4 & 18.4 & 23.2 \\
Heshui & 66 & 41.2 & 20.8 & 16.9 & 21.1 \\
Jiyuanan & 123 & 25 & 38.9 & 12.3 & 23.8 \\
Ansai & 31 & 26.8 & 40.6 & 11.4 & 21.2 \\
Sum & 288 & 32.5 & 30.1 & 14.7 & 22.7 \\
\hline
\end{tabular}

To obtain the porosity and permeability distributions in Chang 7 reservoir, a number of core samples from the formation layers of four blocks of Maling, Heshui, Jiyuan, Ansai were collected and 
the porosity and permeability of the cores were measured. The core data, together with the reservoir well logging results, were used to draw the porosity and permeability maps. Table 2 shows the coring details, Figure 6 shows the porosity distributions for the blocks of Maling, Heshui, Jiyuan and Ansai, Figure 7 shows the permeability results. The dots and lines in the figures are the existing wells.

Table 2. The coring details for the analysis of porosity and permeability in Chang 7 reservoir.

\begin{tabular}{ccccc}
\hline Blocks & Formation Layer & Number of Core Samples & Average Porosity [\%] & Average Permeability [mD] \\
\hline Maling & Chang $7_{2}$ & 2234 & 9.1 & 0.13 \\
Heshui & Chang $7_{1}$ & 2575 & 8.9 & 0.14 \\
Jiyuan & Chang $7_{2}$ & 3455 & 8.9 & 0.12 \\
Ansai & Chang $7_{3}$ & 4067 & 8.1 & 0.11 \\
\hline
\end{tabular}

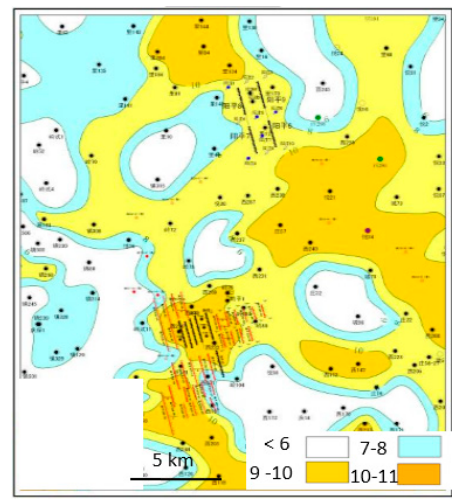

(a)

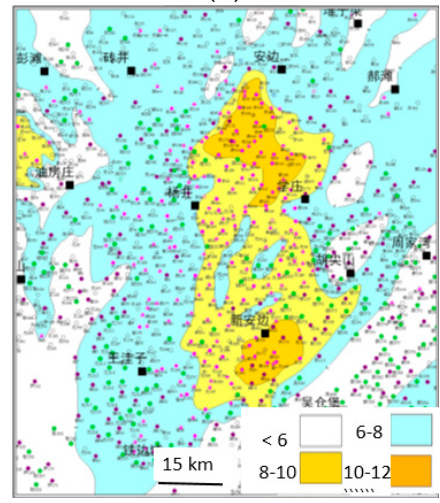

(c)

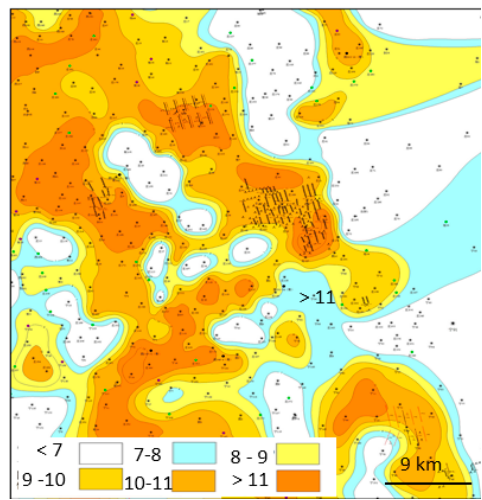

(b)

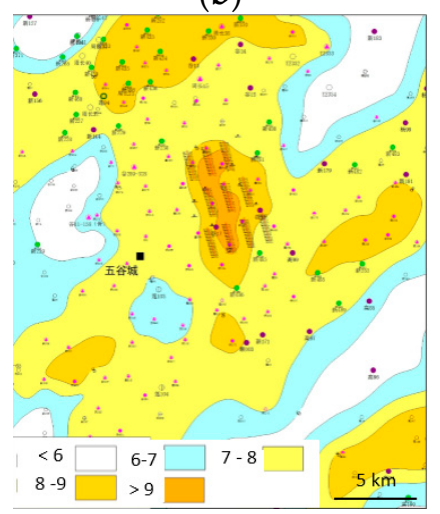

(d)

Figure 6. Porosity (\%) distributions of the four pilot areas in Chang 7: (a) Maling, (b) Heshui, (c) Jiyuan, (d) Ansai.

Porosities of the reservoir formations in Maling, Heshui, Jiyuan, and Ansai mainly distributes in the range of $6-11 \%, 7-11 \%, 6-10 \%$, and $6-9 \%$, respectively. Most of the reservoir formation permeabilities are smaller than $0.2 \mathrm{mD}$ (Figure $7 \mathrm{a}-\mathrm{c}$ ). In Ansai, the formation permeability can be much smaller, as shown in Figure $7 \mathrm{~d}$. The average porosity of Chang 7, as calculated based on the overall core analysis, is around $8-9 \%$, and the average permeability is about $0.11-0.14 \mathrm{mD}$. As can be seen, the Chang 7 reservoir possesses very low porosity and permeability, which are unfavorable for oil production.

The micropore structure of the tight sandstones in the Chang 7 tight oil reservoir was measured using X-ray computed tomography (X-CT). X-CT is a widely used and reliable technology that can rapidly measure the pore structures of tight cores with high accuracy, and the measurement scale of $\mathrm{CT}$ ranges from $\mathrm{nm}$ to $\mu \mathrm{m}$ level. Figure 8 shows the variation in pore volume at different pore radii. The results were obtained based on an X-CT analysis of 52 cores from the Chang 7 reservoir. The pore radius of the Chang 7 tight oil reservoir mainly distributes in the range of 2-10 $\mu \mathrm{m}$. Pores with a radius 
of $2-10 \mu \mathrm{m}$ occupy $76.8 \%$ of the total pore volume in the reservoir and thus are the main storage space for the tight oil.

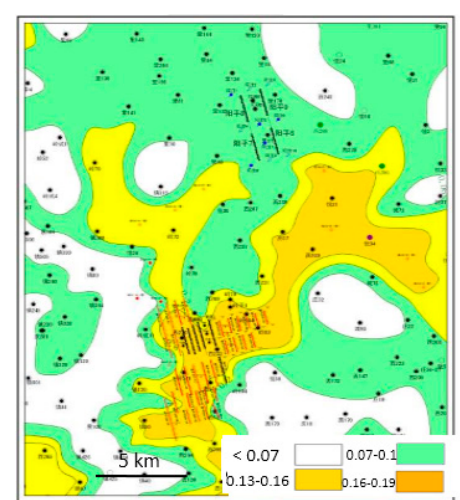

(a)

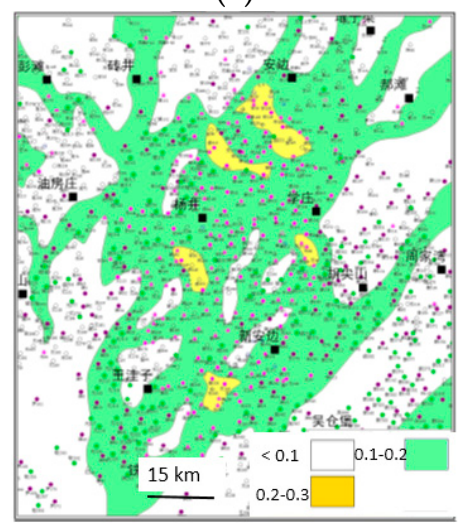

(c)

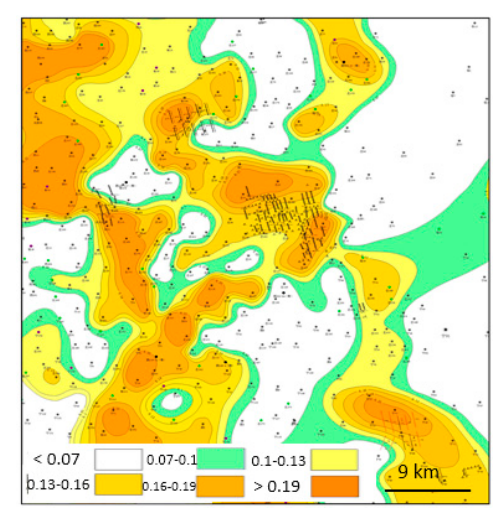

(b)

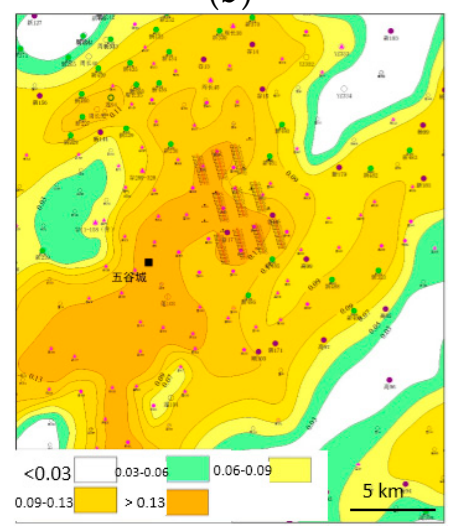

(d)

Figure 7. Permeability (mD) distributions of the four pilot areas in Chang 7: (a) Maling, (b) Heshui, (c) Jiyuan, (d) Ansai.

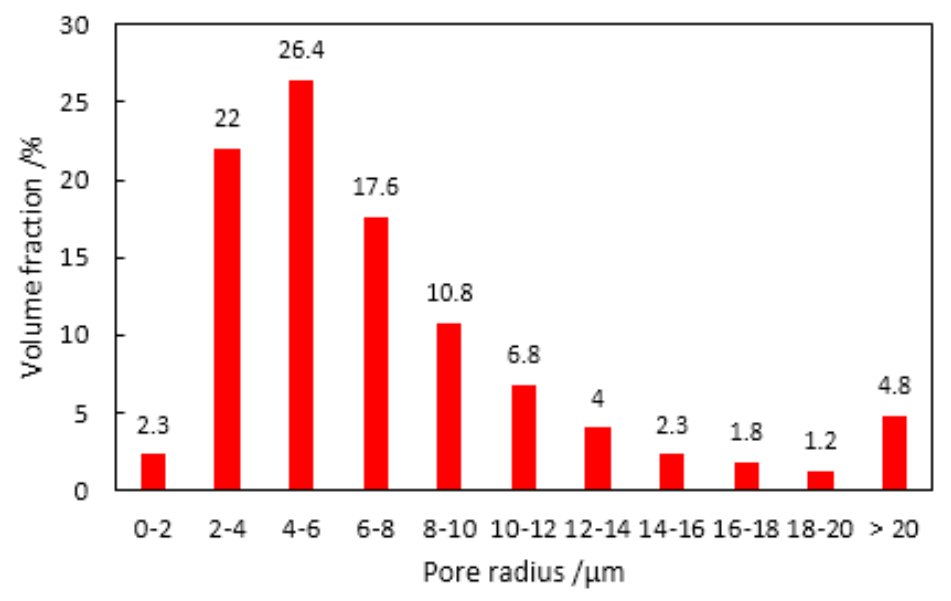

Figure 8. Variation of pore volumes at different pore radius for the tight rocks of Chang 7.

Figure 9 shows the coordination numbers of the pores for the Chang 7 tight oil reservoir. It can be seen that the overall coordination number for the pores is small, mainly concentrating in 1-3. Coordination number characterizes the number of pore throats that connect to one pore body. The smaller coordination number means poorer pore connectivity because, in such case, the pores were connected with fewer throats, which would limit the fluid flowability in the tight porous media. Although most of the pore body radius of Chang 7 reservoir are between $2 \mu \mathrm{m}$ and $10 \mu \mathrm{m}$, and the pore 
throat radius could be much smaller. Results in Figure 8 indicates that it is difficult for the tight oils flowing in the porous media, and thus uneconomic to recover them from the reservoir without further stimulation treatment. To acquire economically feasible tight oils, hydraulic fracturing techniques should be utilized.

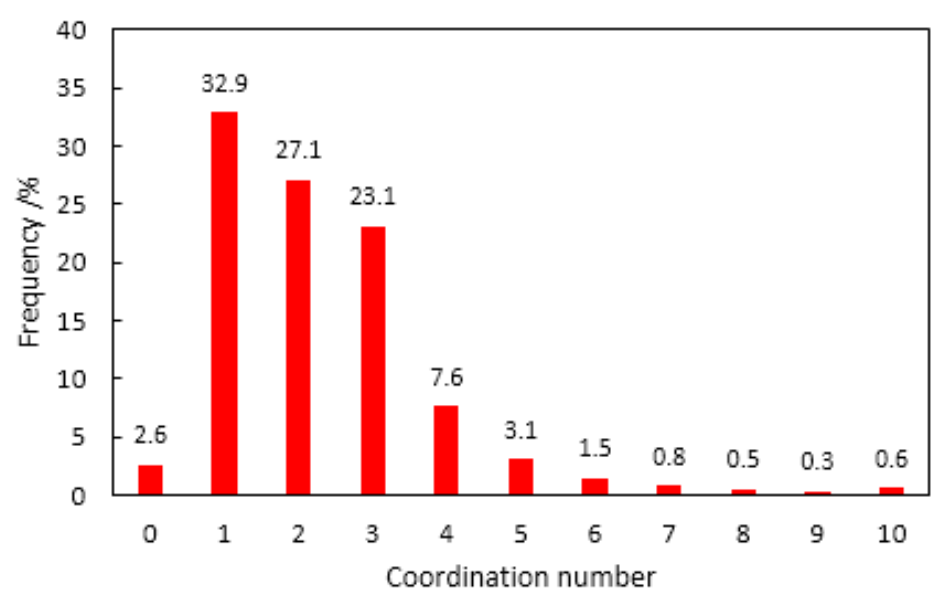

Figure 9. Coordination number for the pores of Chang 7 tight oil reservoir.

\section{Experimental Section for Tight Oil Recovery in Pore-Fracture Dual Media}

\subsection{Flow Conductivity of Pore-Fracture Media and Its Effects on Tight Oil Recovery}

The flow conductivity in a pore-fracture dual medium can be much higher than that in single pore media due to high permeability fractures. In order to investigate the flow behaviors of oil and water in the dual medium, relative permeability measurements were conducted through core flow tests. Because cores with fractures are easily broken, it is difficult to obtain them from the reservoir formations directly. In this study, the unbroken cores from Chang 7 formations, $2.5 \mathrm{~cm}$ in diameter and $6 \mathrm{~cm}$ in length, were compressed using the tri-axial compression method to create different microfractures. During the fracture creating process, we used the trial and error method to make fractured cores which possess appropriate initial permeabilities until the required cores were successfully achieved. The successfully made cores would be then used for the relative permeability tests. The relative permeability of oil and water were measured using the un-steady state method. The change of cumulative production of oil and water with time was recorded carefully to accurately calculate the relative permeability data. Figure 10 shows four typical results for the relative permeability variations of oil and water in the cores with different fractures. Before fracturing, the cores possess similar initial permeability $\left(k_{i}\right)$. The core permeabilities after fracturing $\left(k_{f}\right)$ are mainly determined by the developed fractures. The after-fracturing permeabilities of the core sample (Figure 10a,b) do not increase very much compared to the initial permeabilities. For core sample (Figure 10a), the permeability increases from $0.08 \mathrm{mD}$ to $0.19 \mathrm{mD}$, and for core sample (Figure 10b), it increases from $0.14 \mathrm{mD}$ to $0.36 \mathrm{mD}$. In such cases, the fractures created by the tri-axial compression method in the cores are more likely the pre-existing microfractures in formations. The fractures possess a small size, small number and have limited effects on the fluid flow conductivity increase in the cores. The permeabilities of the core sample (Figure 10c,d) have a significant increase after fracturing, the measured $k_{f}$ can be as high as $5.48 \mathrm{mD}$ and $12.14 \mathrm{mD}$, respectively. In such cases, the created fractures in the cores are more likely the produced fractures by fracturing treatment in formations. Such fractures were more complex and with a larger number and larger size than the fractures in core sample (Figure 10a) and core sample (Figure 10b).

As can be seen in Figure 10, before fracturing, the flow of oil and water occurs in the matrix of the cores. The relative permeability of oil first decreases rapidly with water saturation and then declines slowly. The relative permeability of water increases gradually. The cores possess a wide two-phase 
flow region. After fracturing, due to the developed microfractures, the flow conductivity in all of the cores has a great increment for both oil and water. For cores with slightly increased permeability, sometimes two to three times higher than that before fracturing (Figure 10a,b), the variations of relatively permeabilities for oil and water are similar to that in the un-fractured cores. The relative permeability of oil declines, and the relative permeability of water inclines gradually. The intersection of the two-phase relative permeability curves is higher in the fractured cores, indicating a greater increase in fluid flowability after fracturing. In addition, the fractured cores still have a wide two-phase flow region. If the permeabilities of the cores after fracturing are much higher than that before fracturing, as shown in Figure 10c,d, there is no doubt that flow conductivity in the cores can be improved greatly. However, the relative permeabilities for the oil phase and the water phase change drastically with water saturation in these fractured cores. The two-phase flow region becomes much smaller than the un-fractured cores and the slightly fractured cores. In such cases, a more rapid water breakthrough will occur through these fractures in the cores when flooded with water. Therefore, in order to efficiently increase oil recovery in tight oil formations through fracturing treatments, such fractures with an appropriate flow conductivity should be created. The developed fractures in formations could enhance the fluid flowability.

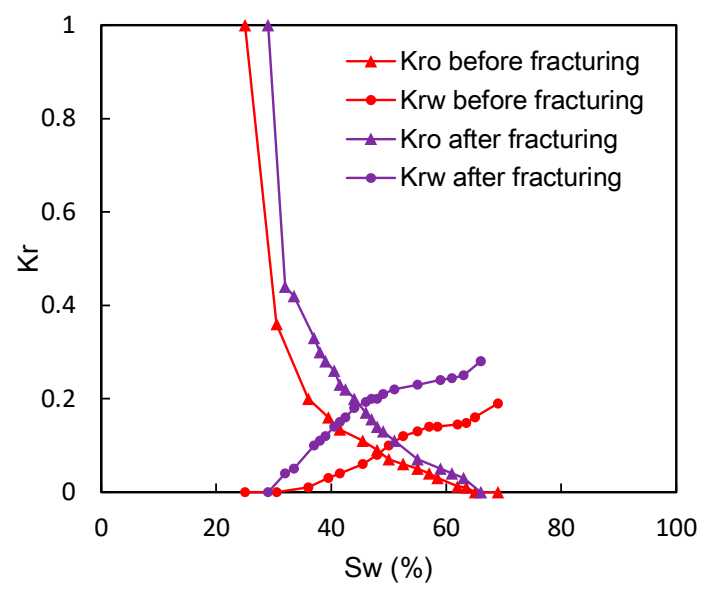

(a)

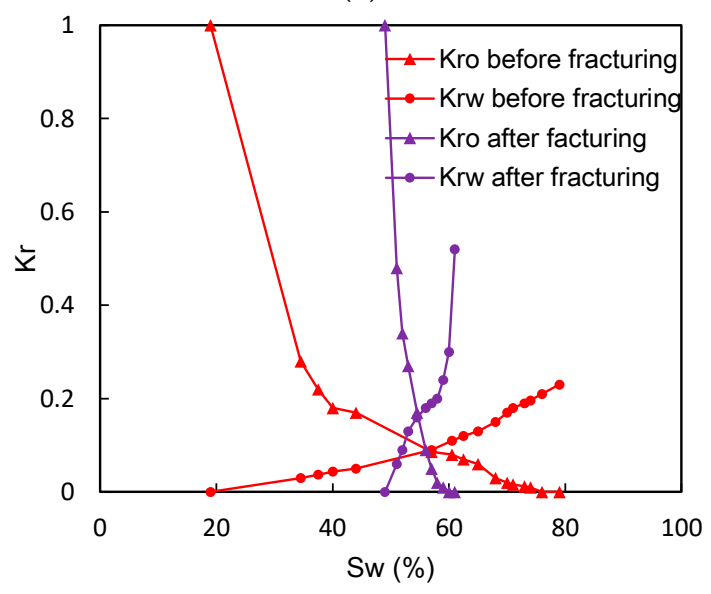

(c)

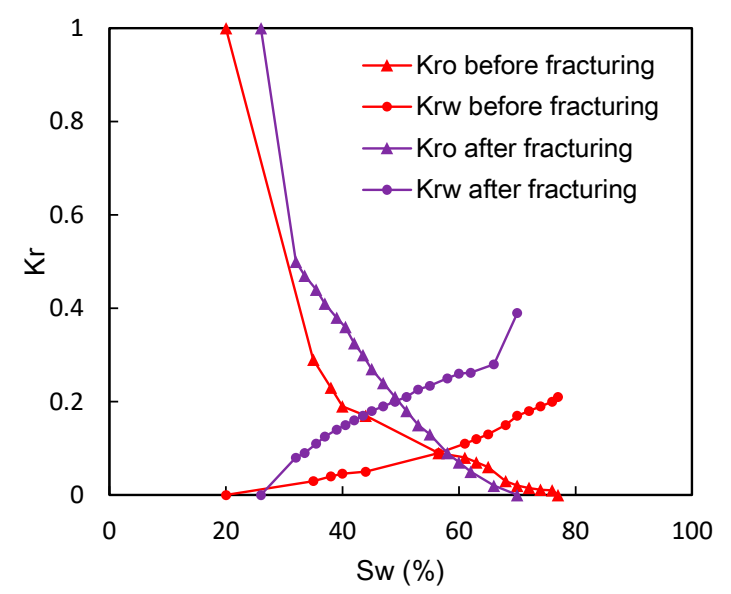

(b)

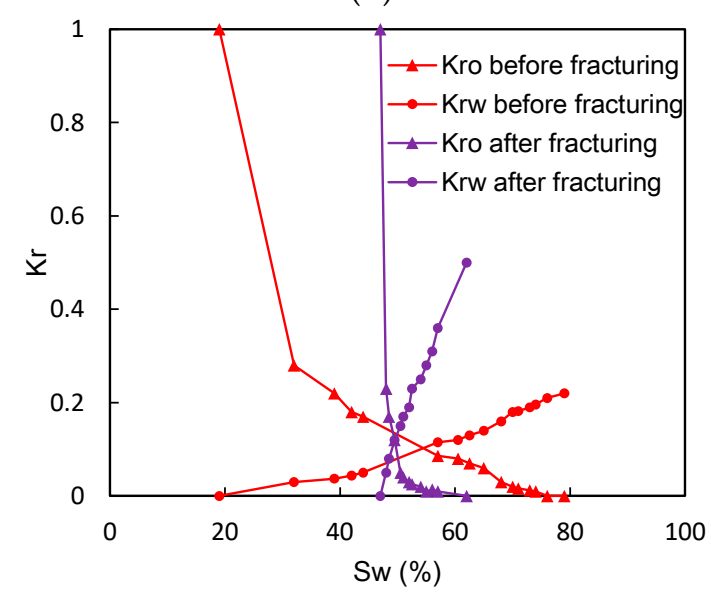

(d)

Figure 10. Relative permeabilities of oil and water in the cores before and after fracturing: (a) $k_{i}=0.08 \mathrm{mD}, k_{f}=0.19 \mathrm{mD}$, (b) $k_{i}=0.14 \mathrm{mD}, k_{f}=0.36 \mathrm{mD}$, (c) $k_{i}=0.07 \mathrm{mD}, k_{f}=5.48 \mathrm{mD}$, (d) $k_{i}=0.07 \mathrm{mD}, k_{f}=12.14 \mathrm{mD}$.

Figure 11 shows the variations of tight oil recoveries in the fractured cores at different permeability ratios of the after-fracturing core permeability to the before-fracturing core permeability $\left(k_{f} / k_{i}\right)$. 


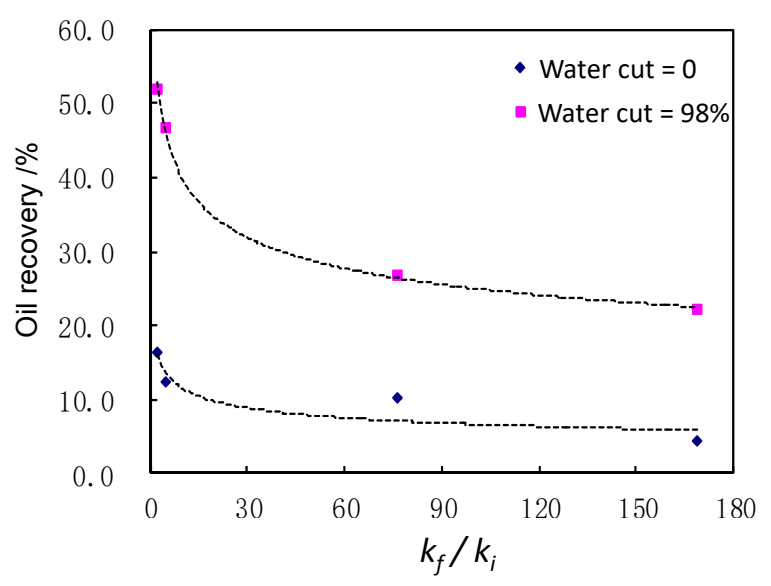

Figure 11. Oil recovery variations with different permeability ratios at different water cuts.

It can be seen that both of the tight oil recoveries of the cores decrease with an increase of the permeability ratio $k_{f} / k_{i}$. Before water breakthrough (water cut $=0$ ), the decrease of oil recovery with permeability ratio is small. However, when water cut $=98 \%$, the tight oil recovery decreases significantly as the permeability ratio increases. This is because the created fractures in the cores possess a higher permeability than the matrix, and due to the small size of the cores, some of the fractures may form through the whole cores from the inlet to the outlet. These fractures could help the oil in the matrix to flow out more easily and thus can improve the oil production rate. However, due to the high conductivity, once the water breaks through from these very high permeability fractures, especially from those that connect the core inlet to the core outlet, the following displacing fluid would be more likely to flow through these highly permeable water channels, rather than flow into the matrix to displace oil. This water channeling problem could be more severe as the permeability of the fractures becomes greater, leaving more residual oil in the tight cores [38]. In the field scale, because of the long distance between the injection well and the production well and the appropriate operations, most of the fractures are unlikely to break through the wells to lead to the water channeling problem. Therefore, fracturing treatment in field can usually result in high oil production rate like the core flooding but may rarely cause the water channeling problem as in the core experiments.

\subsection{Effect of Imbibition on Oil Recovery in Fractured Tight Oil Reservoir}

In conventional oil reservoirs, the oil is flooded out from the pore spaces by the displacing fluids. The oil recovery is improved mainly by the displacement effect. However, in tight oil reservoirs, because of the ultra-low permeability, it is much more difficult for the tight oil to be displaced out by the injected water than the conventional oil. In such reservoirs, apart from the displacement effect, the imbibition of water in the pore spaces plays an important role in tight oil recovery improvement. Fracturing treatment can improve the oil production rate in tight reservoirs. The matrix of reservoir formations provides spaces for tight oil storage, and the created fractures mainly provide highly conductive flow channels for the oil. In the early recovery stage, most of the produced oil comes from the fractures. As the oil in the fractures flows out, the following oil would be mainly from the matrix. In this stage, water in the fractures imbibes into the low permeability matrix to displace tight oil out from the pore spaces. Such an imbibition effect is important for the oil recovery in the fracturing-treatment tight reservoirs, especially when the reservoir is in the mid or late development stages.

Figure 12 shows a detailed schematic of the imbibition effect on oil recovery in a tight porous medium with fractures. Imbibition in pore-fracture dual media can be described as the wetting phase (water) in fractures spontaneously imbibed into the matrix of the tight porous media under the capillary force, replacing the non-wetting phase (oil) in the tight pore spaces. The replaced oil will then enter the fracture systems and finally flow into the wellbore. The complex fractures in tight porous media divide the total matrix into a number of smaller pieces, which provides more interaction areas for the 
water and the oil. Therefore, more displacing water can invade the matrix to replace the oil inside. The imbibition effect would thus be enhanced. As the oil flows out from the matrix, the dense fractures can also provide more flow channels for the replaced oil, which increases the possibility of further movement of the oil.

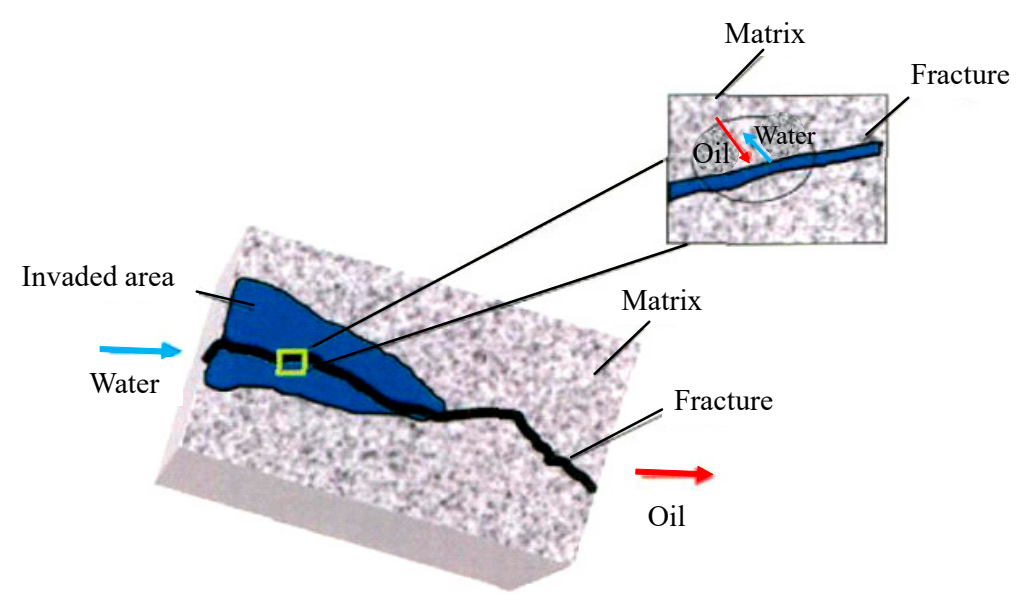

Figure 12. Schematic of the imbibition effect on oil recovery in tight porous media with fractures.

Figure 13 shows a comparison test of the water imbibition rate in tight cores with and without fractures. The permeability of the matrix of the two tight cores is $0.08 \mathrm{mD}$. Fractures in the cores were created using a tri-axial compression apparatus.

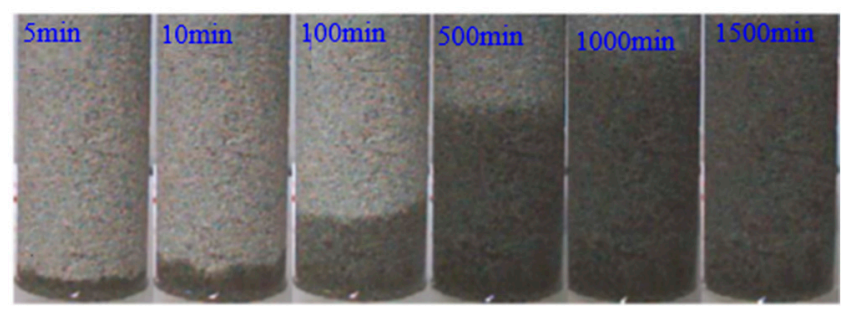

(a)

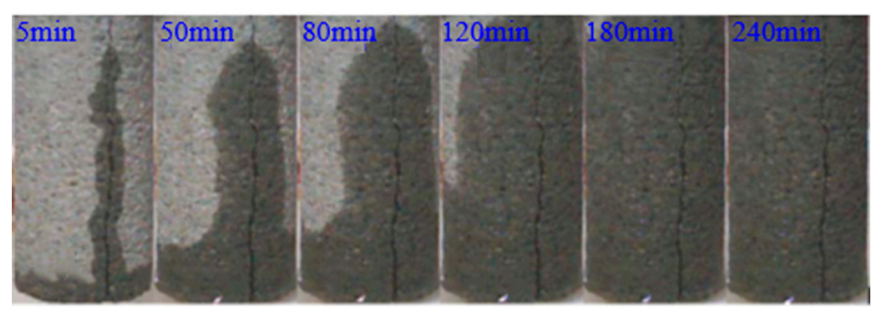

(b)

Figure 13. Images of imbibition rate of water in tight cores: (a) Core without fractures, (b) core with fractures.

As can be seen in Figure 13, the imbibition process in the tight core with fractures is much faster than that in the core without fractures. In the core without fractures, the water was imbibed into the matrix slowly from the bottom. In the core with fractures, the water tended to first enter into the fractures rapidly, and the water then begins to be imbibed into the nearby matrix along the fractures. After about $240 \mathrm{~min}$, the core with fractures can be completely occupied by the imbibed water, more than five times faster than the core without fractures. The fractures in the tight cores can significantly increase the contact areas for the water and the core matrix and thus can improve the imbibition rate in the cores remarkably. Provided that the cores were saturated with oil in advance, a higher oil producing rate enhanced by the imbibition effect can be expected in the fractured cores. 
Capillary pressure is the main driving force of the imbibition effect in tight porous media $[39,40]$. As the capillary pressure is inversely proportional to the capillary radius, the smaller capillary possesses greater capillary pressure in it and thus has a stronger imbibition effect. The average pore diameter for tight porous media can be several to tens of nanometers, which ensures a high capillary force in those pores. To have an effective oil recovery in the fracturing treatment of tight oil reservoirs, the capillary pressure or the imbibition should be high enough to overcome the end effect between the fractures and the matrix. Another thing one should be concerned with is that a smaller pore radius is not always helpful for the imbibition-enhanced oil recovery. In order to effectively replace oil with water in tight porous media, the pore radius should be larger than the thickness of the water adsorption layer on the pore walls.

During the water flooding process in tight oil reservoirs, apart from the displacement effect, oil recovery can also be enhanced by the imbibition effect, as discussed above. To determine the oil recovery factors of the displacement effect and the imbibition effect, flooding tests for Chang 7 tight cores with different permeabilities were performed, and nuclear magnetic resonance (NMR) technology was used to analyze the different oil recoveries.

Figure 14 shows a typical frequency spectrum of the transversal relation time $\left(T_{2}\right)$ measured by NMR for a tight oil core at different oil saturations.

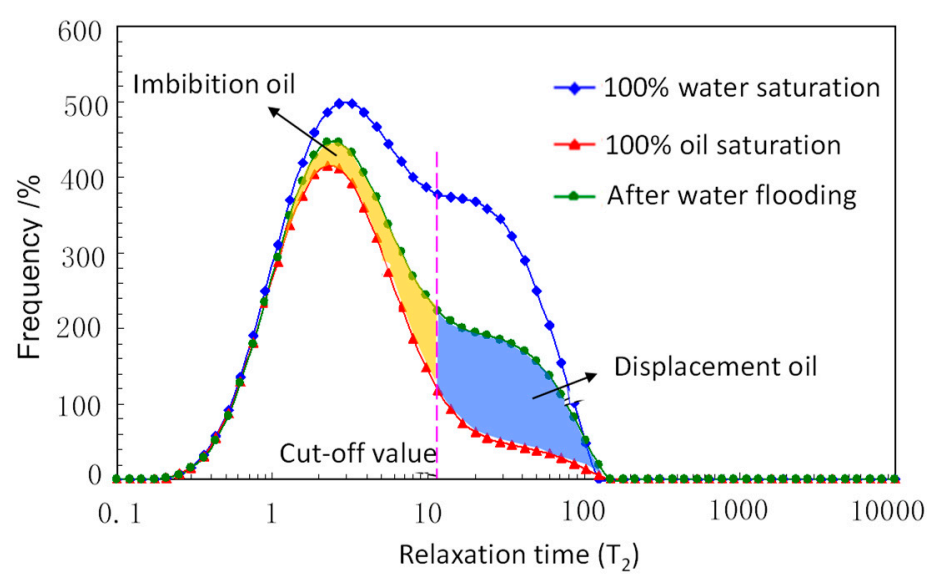

Figure 14. Frequency spectrum of relation time for tight oil core at different oil saturations.

In Figure 14, the area between the $\mathrm{T}_{2}$ frequency at $100 \%$ water saturation (blue curve) and the $\mathrm{T}_{2}$ frequency at $100 \%$ oil saturation (red curve) characterizes the total oil saturation in the tight core. The area between the $T_{2}$ frequency after water flooding (green curve) and the $T_{2}$ frequency at $100 \%$ oil saturation characterizes the total movable oil in the tight core. As can be seen, in tight oil reservoirs, due to the low permeability and poor pore connectivity, a large amount of oil cannot be moved and produced and will remain in the reservoir as residual oil. The water flooding process in tight oil reservoirs is designed to recover the movable oil as much as possible. During the water flooding process, the movable oil is produced both by the water imbibition effect and the water displacement effect. The relaxation time cut-off value was used to characterize the limitation of movable oil recovered by the two different effects [41-43]. As shown in Figure 14, for oil recovered by the imbibition effect (yellow area), the corresponding $T_{2}$ is smaller than the cut-off value, and the corresponding $T_{2}$ is larger than cut-off value.

Based on the NMR analysis of the water flooding tests in the tight cores, oil recoveries improved by the imbibition effect and the displacement effect were obtained. Table 3 shows the detailed movable oil recovery results for the imbibition effect and the displacement effect in 17 tight oil cores from the Chang 7 reservoir. 
Table 3. Movable oil recoveries affected by imbibition and displacement in Chang 7 tight cores.

\begin{tabular}{|c|c|c|c|c|c|c|c|}
\hline \multirow{2}{*}{ Core Number } & \multirow{2}{*}{ Permeability [mD] } & \multirow{2}{*}{ Porosity [\%] } & \multirow{2}{*}{ Total Movable Oil Saturation [\%] } & \multicolumn{2}{|c|}{ Recovered Movable Oil Saturation [\%] } & \multicolumn{2}{|c|}{ Recovery of Movable Oil [\%] } \\
\hline & & & & Imbibition Effect & Displacement Effect & Imbibition Effect & Displacement Effect \\
\hline 1 & 0.014 & 7.5 & 24.42 & 9.81 & 14.61 & 40.17 & 59.83 \\
\hline 2 & 0.014 & 6.7 & 25.45 & 13.06 & 12.39 & 51.32 & 48.68 \\
\hline 3 & 0.015 & 7.1 & 28.42 & 12.77 & 15.65 & 44.93 & 55.07 \\
\hline 4 & 0.034 & 10.1 & 34.21 & 13.21 & 21 & 38.61 & 61.39 \\
\hline 5 & 0.038 & 10.7 & 34.16 & 10.77 & 23.39 & 31.53 & 68.47 \\
\hline 6 & 0.044 & 9.9 & 35.31 & 13.23 & 22.08 & 37.47 & 62.53 \\
\hline 7 & 0.045 & 10.2 & 37.06 & 13.48 & 23.58 & 36.37 & 63.63 \\
\hline 8 & 0.058 & 10.5 & 35.31 & 11.01 & 24.3 & 31.18 & 68.82 \\
\hline 9 & 0.065 & 10.3 & 32.7 & 10.12 & 22.58 & 26.00 & 58.02 \\
\hline 10 & 0.066 & 10 & 38.92 & 10.8 & 28.12 & 28.18 & 73.38 \\
\hline 11 & 0.067 & 11.9 & 38.32 & 9.46 & 28.86 & 24.69 & 75.31 \\
\hline 12 & 0.096 & 11.3 & 36.87 & 6.67 & 30.2 & 18.09 & 81.91 \\
\hline 13 & 0.102 & 11.1 & 37.72 & 5.29 & 32.43 & 14.02 & 85.98 \\
\hline 14 & 0.104 & 10.7 & 34.81 & 3.23 & 31.58 & 9.28 & 90.72 \\
\hline 15 & 0.108 & 11.7 & 39.04 & 5.22 & 33.82 & 13.37 & 86.63 \\
\hline 16 & 0.135 & 10.9 & 39.79 & 2.12 & 37.67 & 5.33 & 94.67 \\
\hline 17 & 0.143 & 8.6 & 36.01 & 4.59 & 31.42 & 12.75 & 87.25 \\
\hline
\end{tabular}


As we can see in Table 3, because of the low permeability, the tight cores obtained from the Chang 7 reservoir possess a low movable oil saturation $(<40 \%)$. During the water flooding process, the imbibition effect could have a significant contribution to the movable oil recovery in the tight cores, as about $5.33-51.32 \%$ of the movable oil recovery was improved by the water imbibition. It can also be seen in Table 3 that the imbibition effect in tight cores decreases with the increase in core permeability. In the cores with lower permeabilities, e.g., where $\mathrm{k}<0.06 \mathrm{mD}$, a large portion of movable oil (around $30-50 \%$ ) could be recovered by the imbibition effect. In cores with higher permeabilities, the water displacement takes a much more predominant effect.

The measurements and experimental tests in this study can provide instructive data to further reservoir simulation and optimization operations. The permeability, porosity and pore structure distribution data obtained from thousands of core sample analysis could help to enhance the reliability of the accurate description for the physical properties of reservoir formations. The relative permeability tests provided useful data for the analysis of flow behavior of tight oil and water in pore-fracture dual media. The EOR results from core flooding experiments could give instructions to the pilot operations during the fracturing treatments, i.e., when enhancing oil recovery in tight oil reservoirs using fracturing treatment, on one hand, the developed high permeability fractures could increase the oil production rate, on the other hand, such existing high permeability channels could lead to a higher water cut and a smaller final oil recovery factor. Thus, creating proper fractures considering both the production rate and final oil recovery is of great significance to the application of fracturing in tight oil reservoirs.

\section{Field Practice of Volume Fracturing Treatment}

\subsection{Field Development Stages in the Chang 7 Reservoir}

The field development in the Chang 7 tight oil reservoir has experienced four stages. The first is the directional well development stage. Directional well tests were conducted from 2010 to 2011. During this stage, water injection accompanied by multistage sand fracturing in directional wells was performed. The average amount of ceramic proppant injected into each well was $32.1 \mathrm{~m}^{3}$. The sand ratio in the fracturing fluid was $29.8 \%$, and the fluid injection rate was $2.0 \mathrm{~m}^{3} / \mathrm{min}$. The production rate in the treated directional wells was low, about 1.5 ton/day in every well, indicating little improvement to the tight oil recovery.

To solve the problem of the low production rate in the directional wells, in 2011, conventional fracturing treatment in horizontal wells was tried in the Chang 7 reservoir. The fluid injection rate of the conventional fracturing was smaller than $6 \mathrm{~m}^{3} / \mathrm{min}$. The production results in six treated horizontal wells showed that a significant oil production rate improvement can be obtained in the early well production stage, reaching about 5.3 ton/day in every well. However, the wells were soon watered out and oil production rate dropped rapidly.

In 2012, the volume fracturing pilot test in the Chang 7 reservoir was carried out. Twenty-four horizontal wells were treated by volume fracturing during this stage. Compared with conventional fracturing, the fluid injection rate of volume fracturing was higher than $6 \mathrm{~m}^{3} / \mathrm{min}$, with a larger injected fracturing fluid volume. After volume fracturing treatment, the oil production rate in horizontal wells can be markedly increased to as high as 10 ton/day, almost twice as high compared with the conventional fracturing treatment. In Chang 7 reservoir, a segmented multi-cluster fracturing with fast-drilling bridge plugs technique was applied during the volume fracturing treatment [38], as shown in Figure 15. The long horizontal well was divided into several intervals by bridge plugs, and three to five clusters perforations were performed in every interval. The multi-cluster perforations can support the large volume fluid injection which is required to form a great number of complex fractures. In addition, due to the shorter inter-fracture distance in the multi-cluster fracturing, the interference between them can generate more complex fracture networks [25]. In Chang 7 reservoir, the formation rocks possess a high brittleness as the quartz, feldspar and lithic fragment composed over $70 \%$ of the 
rocks, which are more easily to form a great number of complex fractures during the large volume injection fracturing treatments.

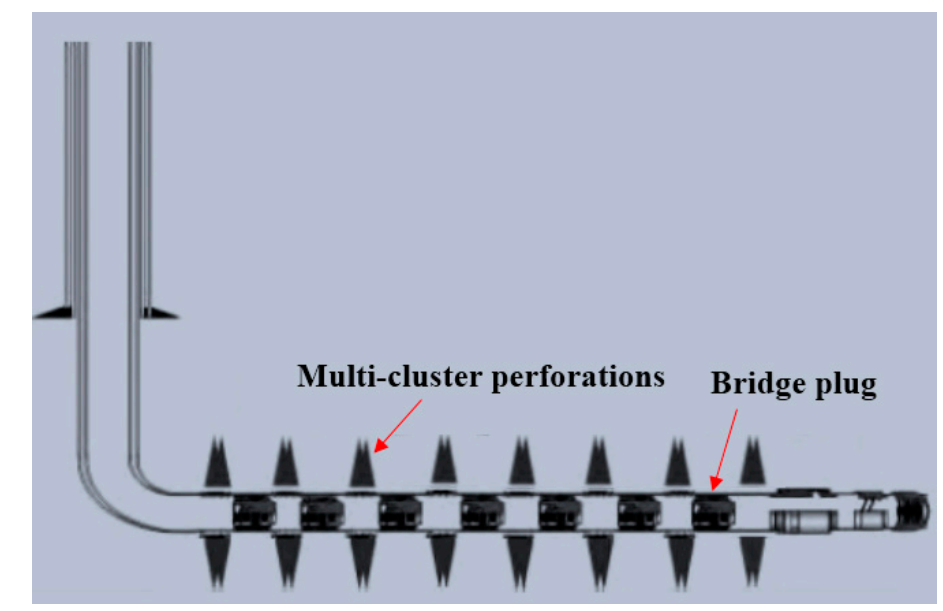

Figure 15. Schematic of the segmented multi-cluster fracturing technique with bridge plugs.

Considering the significant promotion of oil production with the pilot volume fracturing treatment, a large-scale field application of hydraulic volume fracturing in four blocks in the Chang 7 reservoir was launched from 2013 to 2016. By the end of 2016, 414 wells in Chang 7 had been treated with volume fracturing. The average oil production rate of the treated wells was 9.6 ton/day per well for the first three months. So far, the total tight oil production in these wells has been $3.203 \times 10^{6}$ ton.

\subsection{Tight Oil Production in Volume-Fracturing-Treated Wells}

Table 4 shows a set of well stimulation results by the volume fracturing treatments in the Chang 7 tight oil reservoir. Fractures parameters were obtained through the application of microseismic monitoring technology. $S R V_{f}$ represents stimulated reservoir volume by conventional fracturing treatment, and $S R V v_{f}$ represents stimulated reservoir volume by volume fracturing treatment. It can be seen that the volume fracturing treatments in the wells possessed a higher fluid injection rate, a lower sand ratio, and a larger reservoir stimulation volume than the conventional fracturing. The average injection rate of volume fracturing in 12 treated wells was about $8.8 \mathrm{~m}^{3} / \mathrm{min}$, almost four times that of the conventional fracturing. The sand ratios, which ranged from 8.5 to $14.3 \%$, were less than half those in conventional fracturing. The volume fracturing treatment in wells formed favorable fractures in the formation. The average half-length, width, and height of the fractures created by volume fracturing treatments were all larger than those in conventional fracturing treatments, indicating an improvement in the fluid flow in the fractures. Due to the proper parameter design, such as large sand and fluid injection volume, low sand ratio, high injection rate, and so on, and the appropriate well operations, volume fracturing could lead to a larger fracture distribution around the treated wells. The volume fracturing treatment design overall resulted in the greater SRV in the reservoir, i.e., the largest $\mathrm{SRV}_{\mathrm{vf}}$ in the treated wells was 4.9 times greater than the $S_{R V}$, which also benefits the fluid flow and the final oil production. 
Table 4. Reservoir stimulation results of volume fracturing treatments in Chang 7.

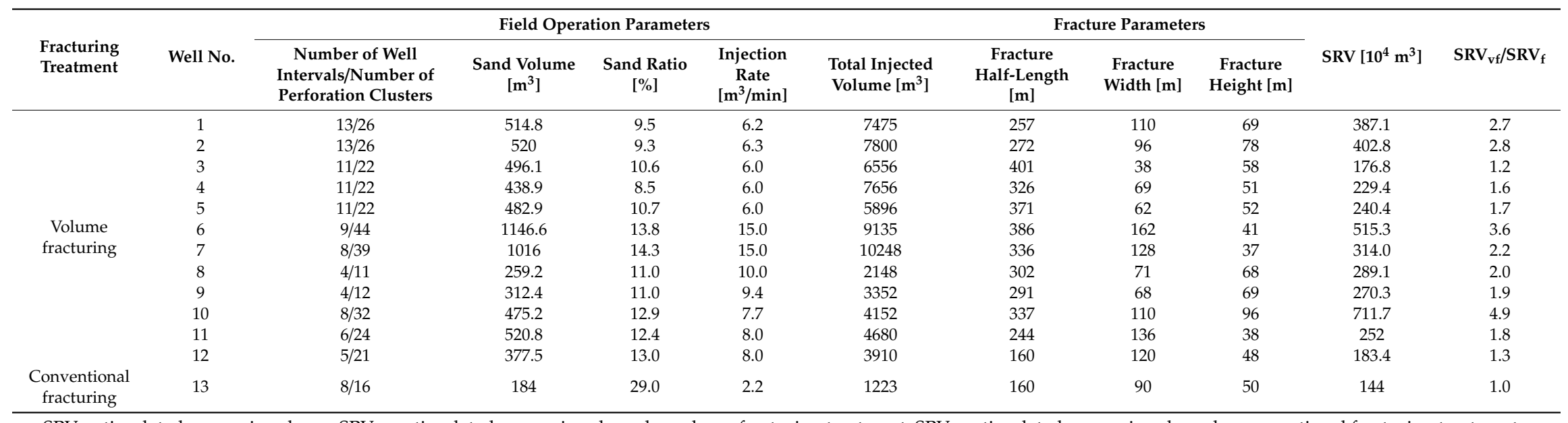

$\mathrm{SRV}$-stimulated reservoir volume, $\mathrm{SRV}_{\mathrm{vf}}$-stimulated reservoir volume by volume fracturing treatment, $\mathrm{SRV}_{\mathrm{f}}$-stimulated reservoir volume by conventional fracturing treatment. 
Volume fracturing is always accompanied by large fluid injection volume, it also has a characteristic of low backflow rate. During the fracturing treatment, most of the fracturing fluid was retained in the formations, which could increase the formation pressures. In Chang 7 reservoir, the average formation pressure, $P_{i}$, is $15.8 \mathrm{MPa}$. Bai et al. [35] investigated the variation of fracture net pressure with the change of injection rate in formation layers with different thickness during hydraulic fracturing treatment in Chang 7 reservoir. Figure 16 summarized characteristics of the net pressure variation in formation fractures at different injection rates. As we can see, increasing the injection rate can improve the net pressure in the formed fractures.

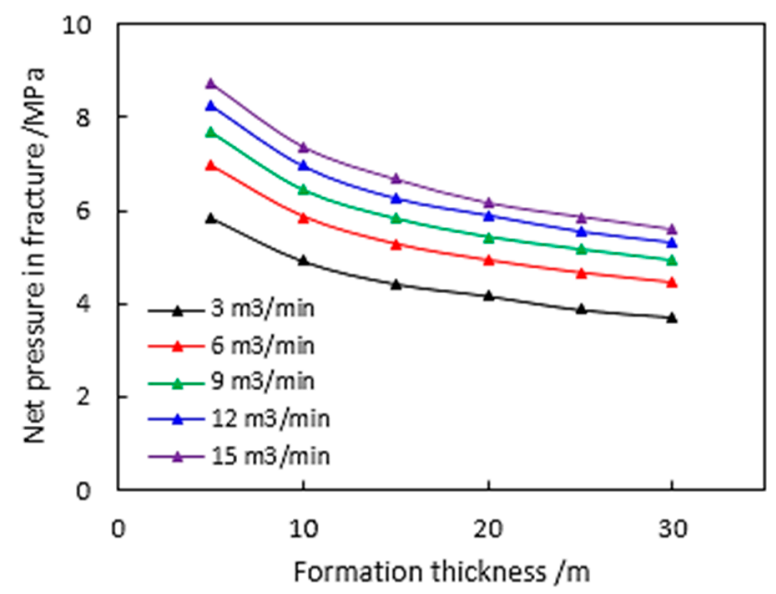

Figure 16. Variation of net pressures in formed fractures with the change of injection rate in formation layers with different thickness during fracturing treatments.

After injecting large volume fracturing fluid, the average formation pressures, $P$, in different blocks increased. Table 5 gives the formation pressure data during the volume fracturing treatments in some of the pilot areas. The pressures were obtained based on both the direct pressure measurements and simulation results.

Table 5. Formation pressures during volume fracturing treatments in Chang 7.

\begin{tabular}{|c|c|c|c|c|c|c|c|}
\hline $\begin{array}{l}\text { Pilot } \\
\text { Areas }\end{array}$ & $\begin{array}{l}\text { Number } \\
\text { of Wells }\end{array}$ & $\begin{array}{c}\text { Average Length } \\
\text { of Horizontal } \\
\text { Well [m] }\end{array}$ & $\begin{array}{c}\text { Fluid Injection } \\
\text { Volume per Well } \\
{\left[\mathrm{m}^{3}\right]}\end{array}$ & $\begin{array}{c}\text { Fluid Backflow } \\
\text { Volume per } \\
\text { Well }\left[\mathrm{m}^{3}\right]\end{array}$ & $\begin{array}{c}\text { Backflow Rate } \\
{[\%]}\end{array}$ & $\begin{array}{c}\text { Fluid Volume } \\
\text { Retained in } \\
\text { Formation }\left[\mathrm{m}^{3}\right]\end{array}$ & $\mathrm{P} / \mathrm{Pi}[\%]$ \\
\hline Jiyuan & 173 & 789 & 5463 & 1672 & 30.6 & 3791 & 119 \\
\hline Heshui & 56 & 976 & 5805 & 1623 & 28.0 & 4182 & 119 \\
\hline Maling & 39 & 1264 & 9294 & 3263 & 35.1 & 6031 & 127 \\
\hline
\end{tabular}

In 2011, six horizontal wells in Jiyuan pilot areas were treated by conventional fracturing with low fluid injection volume and low injection rate. The average oil production rate in the wells was 5.3 ton/day, and the production wells were quickly flooded after a few months. In 2012, 24 horizontal wells in Jiyuan pilot areas were treated by volume fracturing. After the treatment, the average oil production rate in the wells reached to 12 ton/day, twice larger than that of the conventional fracturing treatment. After 2012, a number of horizontal wells in Jiyuan, Heshui, and Maling were treated with volume fracturing. The average daily oil rate after one-year production in the treated wells were still higher than eight tons, which indicating a slowly decrease in oil productivity. Table 6 shows a summary of the decline rate of oil production in conventional fracturing and volume fracturing horizontal wells. As we can see, after one-year production, the average oil decline rate in volume fracturing wells is lower than that in conventional fracturing wells. Figure 17 shows a typical comparison of the one-year tight oil production results in two horizontal wells treated by volume fracturing and conventional fracturing in the Chang 7 reservoir. As can be seen, the volume fracturing treatment in horizontal wells can significantly increase tight oil production. In the first month, the average daily oil production of the 
volume-fracturing-treated wells was more than twice that of the conventional-fracturing-treated wells. The daily oil production decreased with the production time in both types of treated wells. Compared with conventional fracturing, the tight oil production in the wells treated by volume fracturing had a slower decreasing rate. By the end of one year, the daily oil production of the volume-fracturing-treated wells had declined from 12.3 to 7.6 ton/day, about a $38 \%$ decrease. The daily oil production of the conventional-fracturing-treated wells had a more remarkable decrease of $55 \%$, from 5.15 to 2.3 ton/day. The one-year-accumulated tight oil production of the volume-fracturing-treated wells was as high as $3500 \mathrm{t}$, about 2.3 times larger than that of the conventional-fracturing-treated wells, as shown in Figure $17 \mathrm{~b}$.

Table 6. Decline of oil production in conventional fracturing and volume fracturing horizontal wells.

\begin{tabular}{cccccccc}
\hline $\begin{array}{c}\text { Fracturing } \\
\text { Treatment }\end{array}$ & $\begin{array}{c}\text { Number } \\
\text { of Wells }\end{array}$ & Pilot Areas & $\begin{array}{c}\text { Well Length } \\
{[\mathrm{m}]}\end{array}$ & $\begin{array}{c}\text { Sand Volume } \\
\text { per Well }\left[\mathbf{m}^{3}\right]\end{array}$ & $\begin{array}{c}\text { Injection } \\
\text { Rate } \\
{\left[\mathbf{m}^{3} / \mathbf{m i n}\right]}\end{array}$ & $\begin{array}{c}\text { Fluid Injection } \\
\text { Volume per Well } \\
{\left[\mathbf{m}^{3}\right]}\end{array}$ & $\begin{array}{c}\text { One-year oil } \\
\text { Production } \\
\text { Decline Rate [\%] }\end{array}$ \\
\hline $\begin{array}{c}\text { Conventional } \\
\text { fracturing }\end{array}$ & 5 & Jiyuan & $<1000$ & 174.2 & 2.1 & 974.2 & 57.3 \\
\hline $\begin{array}{c}\text { Volume } \\
\text { fracturing }\end{array}$ & 37 & $\begin{array}{c}\text { Maling, Heshui, } \\
\text { Jiyuan }\end{array}$ & 1500 & 763 & 7.1 & 12511 & 8791 \\
\hline
\end{tabular}

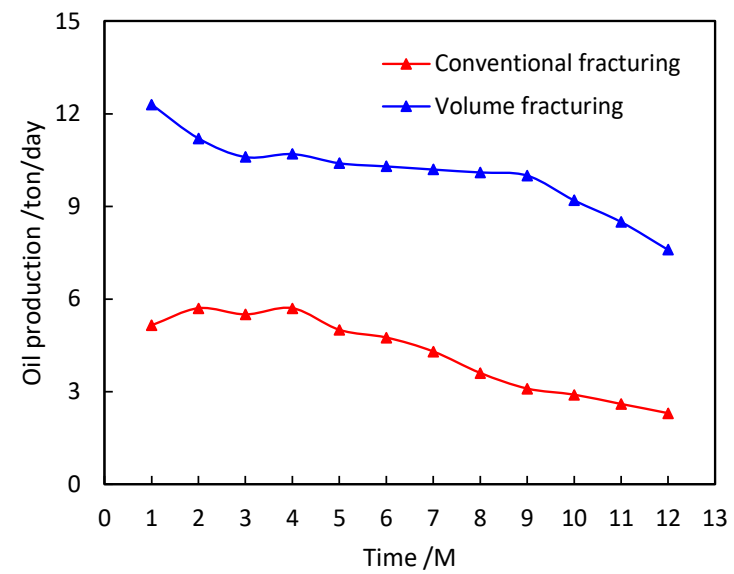

(a)

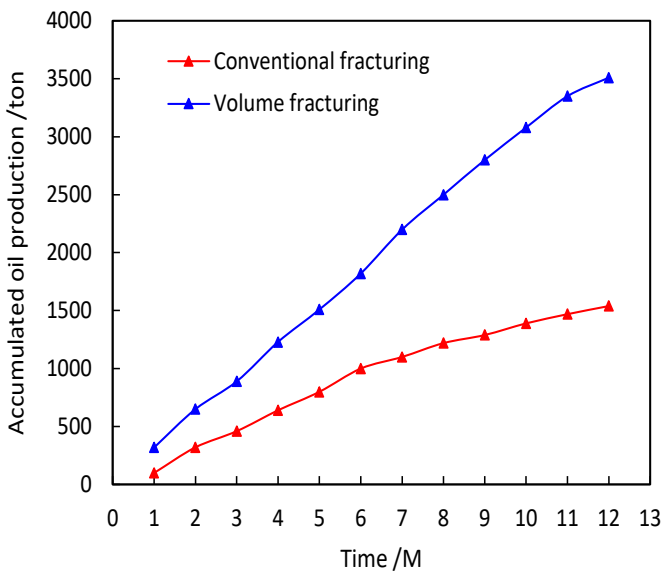

(b)

Figure 17. One-year tight oil production results in wells after volume fracturing treatment and in wells after conventional fracturing treatment: (a) Daily tight oil production, (b) accumulated tight oil production.

\section{Conclusions}

In this work, the performance of the volume fracturing treatment to enhance tight oil recovery in the Chang 7 tight oil reservoir, the Changqing oilfield, was studied through experimental investigation and field-scale practice. Conclusions drawn from this study are as follows:

(1) The Chang 7 tight oil reservoir in the Changqing oilfield possesses a wide distribution of hydrocarbon source rocks that are rich in organic matter. The tight oil generation intensity of the Chang 7 reservoir is estimated to be $495 \times 10^{4} \mathrm{~km}^{2}$, and the total amount of generated hydrocarbons can be as high as $2473.08 \times 10^{8}$ ton. The favorable hydrocarbon source rocks in the Chang 7 reservoir ensures a high capacity of tight oil generation and accumulation.

(2) Core analysis from the pilot areas of the Chang 7 tight oil reservoir indicates poor physical properties of the reservoir formations. The average porosity of the formations is around $8-9 \%$, and average permeability is about $0.11-0.14 \mathrm{mD}$. Due to the low porosity, low permeability, and poor pore connectivity, it is difficult to recover the tight oil from formations without fracturing treatment. 
(3) Fractures developed in tight cores can significantly improve fluid flow conductivity. The increased flowability is crucial to oil recovery improvement in tight oil reservoirs. However, fractures with permeabilities too high above those of the matrix may lead to a severe water channeling problem in the formation. The injected displacing water mainly flows through the fractures with overly high permeability, leaving the tight oil in the matrix almost un-swept. Therefore, when applying fracturing treatment to improve the oil recovery in tight oil reservoirs, developing fractures with appropriate permeabilities, which increases the flowability and decreases the water channeling possibility, is important for field operators.

(4) The imbibition effect plays an important role in tight oil recovery enhancement in low-permeability porous media. Core experiments show that developed fractures can remarkably increase the imbibition rate in tight cores, as the contact area between the fracture and the matrix is significantly increased by the formed fractures. In some fractured Chang 7 tight cores, the movable oil recovery improved by the water imbibition effect can be as high as $51.32 \%$. The imbibition effect in tight cores increases with the decrease in core permeability.

(5) A field-scale application of the volume fracturing treatment exhibits a prominent increase in tight oil production in the Chang 7 reservoir. Compared with the conventional fracturing treatment, volume fracturing can produce a larger number of fractures with more favorable properties to improve the flow conductivity. Moreover, volume fracturing treatment in horizontal wells resulted in a much larger stimulated reservoir volume around the treated wells, which can be 4.9 times greater than that of conventional volume fracturing.

Author Contributions: Conceptualization, J.W. and L.Y.; methodology, C.W.; validation, J.W., L.Y. and C.W.; formal analysis, L.Y.; investigation, L.Y.; resources, C.W. and D.C.; data curation, C.W. and D.C.; writing-original draft preparation, L.Y.; writing—review and editing, J.W.; supervision, J.W.; project administration, J.W. and C.W.; funding acquisition, J.W.

Funding: This research was funded by National Natural Science Foundation of China (51804283), the Fundamental Research Funds for the Central Universities (CUG170652) and the National Natural Science Foundation of Hubei Province (2017CFB345).

Acknowledgments: The authors would like to acknowledge the China University of Geosciences for supporting this research. We also acknowledge the National Natural Science Foundation of China (51804283), the Fundamental Research Funds for the Central Universities (CUG170652) and the National Natural Science Foundation of Hubei Province (2017CFB345) for providing research funding.

Conflicts of Interest: The authors declare no conflict of interest.

\section{References}

1. Wei, M.Q.; Duan, Y.G.; Dong, M.Z.; Fang, Q.T.; Dejam, M. Transient production decline behavior analysis for a multi-fractured horizontal well with discrete fracture networks in shale gas reservoirs. J. Porous Media 2019, 22, 343-361. [CrossRef]

2. Vengosh, A.; Jackson, R.B.; Warner, N.; Darrah, T.H.; Kondash, A. A critical review of the risks to water resources from unconventional shale gas development and hydraulic fracturing in the United States. Environ. Sci. Technol. 2014, 48, 8334-8348. [CrossRef] [PubMed]

3. Wang, Q.; Chen, X.; Jha, A.N.; Rogers, H. Natural gas from shale formation-The evolution, evidences and challenges of shale gas revolution in United States. Renew. Sustain. Energy Rev. 2014, 30, 1-28. [CrossRef]

4. $\quad$ Dong, D.Z.; Wang, Y.M.; Li, X.J.; Zou, C.N.; Guan, Q.Z.; Zhang, C.C.; Huang, J.L.; Wang, S.F.; Wang, H.Y.; Liu, H.L.; et al. Breakthrough and prospect of shale gas exploration and development in China. Nat. Gas Ind. B 2016, 3, 12-26. (In Chinese) [CrossRef]

5. Wang, J.J.; Wang, B.E.; Li, Y.J.; Yang, Z.H.; Gong, H.J.; Dong, M.Z. Measurement of Dynamic Adsorption-Diffusion Process of Methane in Shale. Fuel 2016, 172, 37-48. [CrossRef]

6. Wang, J.J.; Dong, M.Z.; Yang, Z.H.; Gong, H.J.; Li, Y.J. Investigation of methane desorption and its effect on the gas production process from shale: Experimental and mathematical study. Energy Fuel. 2017, 31, $205-216$. [CrossRef] 
7. Zhao, X.G.; Kang, J.L.; Lan, B. Focus on the development of shale gas in China-Based on SWOT analysis. Renew. Sustain. Energy Rev. 2013, 21, 603-613. [CrossRef]

8. Zhao, Y.L.; Zhang, L.H.; Luo, J.X.; Zhang, B.N. Performance of fractured horizontal well with stimulated reservoir volume in unconventional gas reservoir. J. Hydrol. 2014, 512, 447-456. [CrossRef]

9. Mao, R.; Feng, Z.; Liu, Z.; Zhao, Y. Laboratory hydraulic fracturing test on large-scale pre-cracked granite specimens. J. Nat. Gas Sci. Eng. 2017, 44, 278-286. [CrossRef]

10. Bohloli, B.; De Pater, C.J. Experimental study on hydraulic fracturing of soft rocks: Influence of fluid rheology and confining stress. J. Nat. Gas Sci. Eng. 2006, 53, 1-12. [CrossRef]

11. Vidic, R.D.; Brantley, S.L.; Vandenbossche, J.M.; Yoxtheimer, D.; Abad, J.D. Impact of shale gas development on regional water quality. Science 2013, 340, 1235009. [CrossRef] [PubMed]

12. Su, Y.L.; Zhang, Q.; Wang, W.D.; Sheng, G.L. Performance analysis of a composite dual-porosity model in multi-scale fractured shale reservoir. J. Nat. Gas Sci. Eng. 2015, 26, 1107-1118. [CrossRef]

13. Su, Y.L.; Sheng, G.L.; Wang, W.D.; Zhang, Q.; Lu, M.J.; Ren, L. A mixed-fractal flow model for stimulated fractured vertical wells in tight oil reservoirs. Fractals 2016, 24, 1650006. [CrossRef]

14. Rahm, D. Regulating hydraulic fracturing in shale gas plays: The case of Texas. Energy Policy 2011, 39, 2974-2981. [CrossRef]

15. Hummel, N.; Shapiro, S.A. Nonlinear diffusion-based interpretation of induced microseismicity: A Barnett Shale hydraulic fracturing case study nonlinear diffusion and fracturing of shales. Geophysics 2013, 78, B211-B226. [CrossRef]

16. Blanton, T.L. An experimental study of interaction between hydraulically induced and pre-existing fractures. In Proceedings of the SPE Unconventional Gas Recovery Symposium, Pittsburgh, PA, USA, 16-18 May 1982; Society of Petroleum Engineers: Pittsburgh, PA, USA, 1982. [CrossRef]

17. Maity, D.; Ciezobka, J. An interpretation of proppant transport within the stimulated rock volume at the hydraulic-fracturing test site in the Permian Basin. SPE Reserv. Eval. Eng. 2019, 22, 477-491. [CrossRef]

18. Cipolla, C.L.; Berntsen, B.A.; Moos, H.; Ginty, W.R.; Jensen, L. Case Study of Hydraulic Fracture Completions in Horizontal Wells, South Arne Field Danish North Sea. In Proceedings of the SPE Asia Pacific Oil and Gas Conference and Exhibition, Brisbane, Australia, 16-18 October 2000; Society of Petroleum Engineers: Brisbane, Australia, 2000. [CrossRef]

19. Luo, S.; Neal, L.; Arulampalam, P.; Ciosek, J.M. Flow regime analysis of multi-stage hydraulically-fractured horizontal wells with reciprocal rate derivative function: Bakken case study. In Proceedings of the Canadian Unconventional Resources and International Petroleum Conference, Calgary, AB, Canada, 19-21 October 2010; Society of Petroleum Engineers: Calgary, AB, Canada, 2010. [CrossRef]

20. Li, H.T.; Deng, J.G.; Liu, W.; Li, Y.; Lin, S. Research on Casing Deformation Failure Mechanism during Volume Fracturing for Tight Oil Reservoir of Horizontal Wells. In Proceedings of the 51st US Rock Mechanics/Geomechanics Symposium, San Francisco, CA, USA, 25-28 June 2017; American Rock Mechanics Association: San Francisco, CA, USA, 2017.

21. Rickman, R.; Mullen, M.J.; Petre, J.E.; Grieser, W.V.; Kundert, D. A Practical Use of Shale Petrophysics for Stimulation Design Optimization: All Shale Plays Are Not Clones of the Barnett Shale. In Proceedings of the SPE Annual Technical Conference and Exhibition, Denver, CO, USA, 21-24 September 2008; Society of Petroleum Engineers: Denver, CO, USA, 2008. [CrossRef]

22. Li, X.W.; Zhang, K.S.; Fan, F.L.; Tang, M.R.; Pu, X.Q.; Wang, W.X.; Li, X.P. Study and experiment on volume fracturing in low pressure tight formation of Ordos Basin. J. Oil Gas Technol. 2013, 35, 142-146, 152, 169. (In Chinese) [CrossRef]

23. Wu, Q.; Xu, Y.; Wang, T.F.; Wang, X.Q. The revolution of reservoir stimulation: An introduction of volume fracturing. Nat. Gas Ind. 2011, 31, 7-12. (In Chinese) [CrossRef]

24. Tabatabaei, M.; Mack, D.J.; Daniels, N.R. Evaluating the Performance of Hydraulically Fractured Horizontal Wells in the Bakken Shale Play. In Proceedings of the SPE Rocky Mountain Petroleum Technology Conference, Denver, CO, USA, 14-16 April 2009; Society of Petroleum Engineers: Denver, CO, USA, 2009. [CrossRef]

25. Wu, Q.; Xu, Y.; Wang, X.Q.; Wang, T.F.; Zhang, S.L. Volume fracturing technology of unconventional reservoirs: Connotation, design optimization and implementation. Petrol. Explor. Dev. 2012, 39, 377-384. [CrossRef] 
26. Wu, Q.; Xu, Y.; Liu, Y.Z.; Ding, Y.H.; Wang, X.Q.; Wang, T.F. The current situation of stimulated reservoir volume for shale in US and its inspiration to China. Oil Drill. Prod. Technol. 2011, 33, 45-51. (In Chinese) [CrossRef]

27. Mayerhofer, M.J.; Lolon, E.; Warpinski, N.R.; Cipolla, C.L.; Walser, D.W.; Rightmire, C.M. What is Stimulated Rock Volume? In Proceedings of the SPE Shale Gas Production Conference, Fort Worth, TX, USA, 16-18 November 2008; Society of Petroleum Engineers: Fort Worth, TX, USA, 2008. [CrossRef]

28. Cipolla, C.L.; Warpinski, N.R.; Mayerhofer, M.J.; Lolon, E.; Vincent, M.C. The Relationship between Fracture Complexity, Reservoir Properties, and Fracture Treatment Design. In Proceedings of the SPE Annual Technical Conference and Exhibition, Denver, CO, USA, 21-24 September 2008; Society of Petroleum Engineers: Denver, CO, USA, 2008. [CrossRef]

29. Chipperfield, S.T.; Wong, J.R.; Warner, D.S.; Cipolla, C.L.; Mayerhofer, M.J.; Lolon, E.P.; Warpinski, N.R. Shear Dilation Diagnostics: A New Approach for Evaluating Tight Gas Stimulation Treatments. In Proceedings of the SPE Hydraulic Fracturing Technology Conference, College Station, TX, USA, 29-31 January 2007; Society of Petroleum Engineers: College Station, TX, USA, 2007.

30. East, L.; Soliman, M.Y.; Augustine, J.R. Methods for enhancing far-field complexity in fracturing operations. SPE Prod. Oper. 2011, 26, 291-303. [CrossRef]

31. Chen, Y.J.; Zhang, M.J.; Li, W.; Wang, H.J.; Zhang, Y. A comparative analysis of investment and benefit between conventional fracturing and fracturing by stimulated reservoir volume (SRV): Case history of gas/shale gas wells in the southern Sichuan basin. Nat. Gas Ind. 2014, 34, 1-5. (In Chinese) [CrossRef]

32. Yu, B.M.; Xu, P.; Chen, J. Study on the seepage characteristics in fractured network porous media. J. Xi'an Shiyou Uni. (Nat. Sci. Ed.) 2007, 22, 21-22, 25, 174-175.

33. Lei, Q.; Xu, Y.; Jiang, T.X.; Ding, Y.H.; Wang, X.Q.; Lu, H.B. "Fracture network" fracturing technique for improving post-fracturing performance of low and ultra-low permeability reservoirs. Acta Pet. Sin. 2009, 30, 237-241. [CrossRef]

34. Niu, X.B.; Feng, S.B.; You, Y.; Liang, X.W.; Xin, H.G.; Dan, W.D.; Li, T.Y.; Ren, J.S. Fracture extension and distribution pattern of volume fracturing in tight reservoir: An analysis based on actual coring data after fracturing. Oil Gas Geol. 2019, 40, 669-677. (In Chinese) [CrossRef]

35. Bai, X.H.; Qi, Y.; Lu, H.J.; Duan, P.H.; Gu, Y.L.; Wu, P.R. Optimization design for volume fracturing of horizontal wells in tight oil reservoir of Ordos Basin. Oil Drill. Prod. Technol. 2015, 37, 83-86. (In Chinese) [CrossRef]

36. Fan, J.M.; Yang, Z.Q.; Li, W.B.; Wang, C.; He, Y.A. Assessment of fracturing treatment of horizontal wells using SRV technique for Chang-7 tight oil reservoir in Ordos Basin. J. China Univ. Pet. (Ed. Nat. Sci.) 2015, 39, 103-110. (In Chinese) [CrossRef]

37. Li, Z.Q.; Zhao, J.Z.; Hu, Y.Q.; Ren, L.; Li, Y. Productivity forecast of tight oil reservoirs after multi-zone stimulated reservoir volume fracturing. Pet. Geol. Recovery Effic. 2016, 23, 134-138. (In Chinese)

38. Li, Z.X.; Li, J.; Qu, X.F.; Li, X.W.; Lei, Q.H.; Fan, J.M. The experiment and recognition of the development of Chang 7 tight oil in Ordos Basin. Nat. Gas Geosci. 2015, 26, 1932-1940. (In Chinese) [CrossRef]

39. Mirzaei-Paiaman, A.; Kord, S.; Hamidpour, E.; Mohammadzadeh, O. Scaling one-and multi-dimensional co-current spontaneous imbibition processes in fractured reservoirs. Fuel 2017, 196, 458-472. [CrossRef]

40. Ghanbari, E.; Dehghanpour, H. The fate of fracturing water: A field and simulation study. Fuel 2016, 163, 282-294. [CrossRef]

41. Xiao, L.; Xiao, Z.X. Analysis of methods for determining NMR T2cutoff and its applicability. Prog. Geophys. 2008, 23, 167-172. (In Chinese) [CrossRef]

42. Shao, W.Z.; Ding, Y.J.; Xiao, F.; Mu, H.W.; Liu, H.B.; Cai, H.; Dong, X.F. On the method of determining T2 cutoff value with the T2 spectrum characteristics. Well Logging Technol. 2009, 33, 430-435. (In Chinese)

43. Li, Z.C. Classification of fractured reservoirs by T2 spectrum nuclear magnetic resonance log. Geophys. Prospect. Pet. 2001, 40, 113-118. (In Chinese)

(C) 2019 by the authors. Licensee MDPI, Basel, Switzerland. This article is an open access article distributed under the terms and conditions of the Creative Commons Attribution (CC BY) license (http://creativecommons.org/licenses/by/4.0/). 